\title{
First report of leaf spot on Prunus salicina caused by Alternaria alternata in China
}

\author{
Haijiang Long ${ }^{1} \cdot$ Sen Yang $^{1} \cdot$ Xianhui Yin $^{1,2}\left({ }^{10} \cdot\right.$ Zhibo Zhao $^{1,2} \cdot$ Youhua Long $^{1,2} \cdot$ Juan Fan $^{1} \cdot$ Ran Shu $^{1} \cdot$ Guifei Gu$^{1}$
}

Received: 6 October 2020 / Accepted: 15 April 2021 / Published online: 19 April 2021

(c) Società Italiana di Patologia Vegetale (S.I.Pa.V.) 2021

Keywords Alternaria alternata $\cdot$ Leaf spot $\cdot$ Prunus salicina $\cdot$ Fungus

During summer-autumn of 2019, leaf spot symptoms were observed on Japanese plum (Prunus salicina Lindl.) plants in Huishui county, Guizhou province, China. Subcircular brown spots evolved in leaf discoloration and necrosis. The disease affected $50 \%$ of the plants, and the estimated yield reduction was 10 to $15 \%$ for each field. Symptomatic tissues were surface disinfected with $70 \%$ ethanol for $45 \mathrm{~s}$ and rinsed with sterile distilled water three times. Small pieces of diseased tissues were transferred to potato dextrose agar (PDA) plates and incubated at $25^{\circ} \mathrm{C}$. The colonies initially appeared grayish white and then turned dark brown. Five single-spore isolates produced conidia with 0 to 2 longitudinal or plagiotropous and 1 to 3 transverse septa, conidia were ovoid or ellipsoidal, measuring 22.1 to $46.5 \times 9.2$ to $13.5 \mu \mathrm{m}$ (average $11.1 \times 31.3 \mu \mathrm{m}, n=50$ ). Based on the morphological characters, the isolates were identified as Alternaria alternata (Fr.) Keissl (Simmons 2007). To confirm the morphological identification, the DNA of the representative isolate HJHB1022 was extracted and the internal transcribed spacer (ITS), the translation elongation factor $1-\alpha($ TEF- $1 \alpha)$, and the RNA polymerase II (RPB2) regions were sequenced (GenBank accession Nos. MW048743, MW145536, MW145537, respectively). A BLASTn analysis exhibited $100 \%$ identity with A. alternata in ITS and RPB2 (MH879767.1, MN593335.1, MN660291.1, MK605877.1, respectively), $98.93 \%$ identity in TEF-1 $\alpha$ region (GenBank accession Nos. MK637432.1 and MN046379.1). To confirm pathogenicity, leaves were stab inoculated by piercing into 1-mm using a sterile needle and applying mycelial disks $(5 \mathrm{~mm})$ with conidia of HJHB1022 on the surface of the

Xianhui Yin

xhyin@gzu.edu.cn

1 Institute of Crop Protection, Guizhou University, Guiyang 550025, China

2 Research Center for Engineering Technology of Kiwifruit, Guizhou University, Guiyang 550025, China wounded area. The control leaves were mock inoculated with sterile PDA. After 7 days, leaf spots were observed on inoculated plants and A. alternata was re-isolated about a frequency of $90 \%$, while the controls showed no symptoms. To our knowledge, this is the first report of A. alternata causing leaf spots on Prunus salicina in China and worldwide (Farr and Rossman 2020).

Supplementary information The online version contains supplementary material available at https://doi.org/10.1007/s42161-021-00839-9.

Acknowledgements This work was supported by Science and Technology Project of Guizhou Province (grant no.QKHZC2406-2019).

Funding Science and Technology Project of Guizhou Province (grant no.QKHZC2406-2019)

\section{Declarations}

Conflicts of interest The authors declare that they have no conflict of interest.

\section{Reference}

Farr DF, Rossman AY Fungal (2020) Databases, U.S. National Fungus Collections, ARS, USDA. Retrieved October 16, 2020, from https:// nt.ars-grin.gov/fungaldatabases/

Simmons EG (2007) Alternaria: an identification manual. CBS Fungal Biodiversity Centre, Utrecht

Publisher's Note Springer Nature remains neutral with regard to jurisdictional claims in published maps and institutional affiliations. 